\title{
Sleeping hours: what is the ideal number and how does age impact this?
}

Jean-Philippe Chaput ${ }^{1-4}$ Caroline Dutil ${ }^{1,3}$ Hugues Sampasa-Kanyinga ${ }^{1,4}$

'Healthy Active Living and Obesity Research Group, Children's Hospital of Eastern Ontario Research Institute, Ottawa, ON, Canada; ${ }^{2}$ Department of Pediatrics, University of Ottawa Ottawa, ON, Canada; ${ }^{3}$ School of Human Kinetics, University of Ottawa, Ottawa, ON, Canada; ${ }^{4}$ School of Epidemiology and Public Health, University of Ottawa, Ottawa, ON, Canada
Correspondence: Jean-Philippe Chaput Healthy Active Living and Obesity Research Group, Children's Hospital of Eastern Ontario Research Institute, 40 I Smyth Road, Ottawa, ON KIH 8LI, Canada

Tel +l 6I37377600 (ext 3683)

Email jpchaput@cheo.on.ca
This article was published in the following Dove Press journal: Nature and Science of Sleep

\begin{abstract}
The objective of this narrative review paper is to discuss about sleep duration needed across the lifespan. Sleep duration varies widely across the lifespan and shows an inverse relationship with age. Sleep duration recommendations issued by public health authorities are important for surveillance and help to inform the population of interventions, policies, and healthy sleep behaviors. However, the ideal amount of sleep required each night can vary between different individuals due to genetic factors and other reasons, and it is important to adapt our recommendations on a case-by-case basis. Sleep duration recommendations (public health approach) are well suited to provide guidance at the population-level standpoint, while advice at the individual level (eg, in clinic) should be individualized to the reality of each person. A generally valid assumption is that individuals obtain the right amount of sleep if they wake up feeling well rested and perform well during the day. Beyond sleep quantity, other important sleep characteristics should be considered such as sleep quality and sleep timing (bedtime and wake-up time). In conclusion, the important inter-individual variability in sleep needs across the life cycle implies that there is no "magic number" for the ideal duration of sleep. However, it is important to continue to promote sleep health for all. Sleep is not a waste of time and should receive the same level of attention as nutrition and exercise in the package for good health.
\end{abstract}

Keywords: sleep, recommendations, guidelines, population heath, public health, life cycle

\section{Introduction}

Sleep is increasingly recognized as a critical component of healthy development and overall health. ${ }^{1-3}$ Healthy sleep comprises many dimensions, including adequate duration, good quality, appropriate timing, and the absence of sleep disorders. ${ }^{4,5}$ Not getting enough sleep at night is generally associated with daytime sleepiness, daytime fatigue, depressed mood, poor daytime functioning, and other health and safety problems. ${ }^{6-9}$ Chronic insufficient sleep has become a concern in many countries, given its association with morbidity and mortality. ${ }^{10,11}$ For example, habitual short sleep duration has been associated with adverse health outcomes including obesity, ${ }^{12}$ type 2 diabetes, ${ }^{13}$ hypertension, ${ }^{14}$ cardiovascular disease, ${ }^{15}$ depression, ${ }^{16}$ and all-cause mortality. ${ }^{17}$ Interest in finding ways to improve sleep patterns of individuals at the population-level standpoint is growing, and experts recommend that sleep should be considered more seriously by public health bodies, ie, given as much attention and resources as nutrition and physical activity. ${ }^{18-20}$

Guidelines on the recommended amount of sleep needed for optimal health exist; they are a vital tool for surveillance, they help inform policies, they can provide a starting point for intervention strategies, and they educate the general public about 
healthy sleep behaviors. However, sleep needs may vary from one person to another at any given age across the lifespan. Additionally, some age groups and populations are more likely to report insufficient sleep duration and may be at greater risk for detrimental health outcomes. ${ }^{5,6,11}$ The objective of this narrative review article is to discuss whether or not an ideal amount of sleep exists for optimal health and how it is impacted by age.

\section{Insufficient sleep across the lifespan}

Insufficient sleep has become widespread over the last decades, especially among adolescents. ${ }^{11,21}$ Both physiological factors and exogenous exposures come into play in explaining insufficient sleep in this age group. Sleep curtailment is often attributed to extrinsic factors, such as artificial light, caffeine use, lack of physical activity, no bedtime rules in the household, and the increased availability of information and communication technologies. ${ }^{22-25}$ In adolescence, insufficient sleep has also been attributed to intrinsic factors such as pubertal hormonal changes, which is associated with a shift toward an evening chronotype ${ }^{26}$ that may also lead to an asynchrony between the biological clock, characterized by a phase delay, and the social clock. ${ }^{27}$ In adolescents, this biological phase delay combined with the social clock, for which the main synchronizer is the fixed and early school start time, contributes to the observed sleep deficits in this population. ${ }^{27}$ The conflict between intrinsic and extrinsic factors, biological time and social time, has been indicated to be greater during adolescence than at any other point in our lives. ${ }^{28}$

Despite some overlap between factors that could explain insufficient sleep among adolescents and adults, such as exposure to artificial light at night, lack of physical activity, caffeine consumption, and poor sleep hygiene, other factors that could specifically be related to insufficient sleep among adults may include but not be limited to work demands, social commitments, health and/or affective problems, and family dynamics (eg, working mothers and children with full agendas). ${ }^{10}$

In the elderly, sleep patterns and distribution undergoes significant quantitative and qualitative changes. Older adults tend to have a harder time falling asleep and more trouble staying asleep. This period of life is often accompanied by a circadian shift to a morning chronotype, as opposed to the evening chronotype change during adolescence, that results in early bedtime and risetime. ${ }^{29}$ Research suggests that the need for sleep may not change with age, but it is the ability to get the needed sleep that decreases with age. ${ }^{10}$ This decreased ability to sleep in older adults is often secondary to their comorbidities and related medications (polypharmacy) rather than normal aging processes per se. ${ }^{30-32}$ Furthermore, the increased frequency of sleep-related disorders in the elderly population contribute to much of the sleep deficiencies observed in this population. ${ }^{33-36}$ Inadequate sleep in the elderly could also be related to other factors, such as life changes (eg, retirement, physical inactivity, decreased social interactions), age-related changes in metabolism, and environmental changes (eg, placement in a nursing home). ${ }^{37}$

A systematic review and meta-analysis reported that in the elderly population both short and long sleep are independently associated with increased risk of cardiovascular-related and cancer-related mortality. ${ }^{38}$ Additionally, adjustments for health conditions in the studies examining the association between sleep duration and mortality risks did not attenuate the strength of the association between long sleep and increased risk of mortality, which suggests that the mechanisms in these associations may differ between long sleep and short sleep duration. ${ }^{38}$ One possible explanation for this association, between long sleep duration and increased risk of non-communicable diseases related mortality, may be related to the increased prevalence of sleep fragmentation in this population. ${ }^{38,39}$ While older adults may report long sleep duration, other sleep characteristics, namely sleep architecture and quality, are altered by sleep fragmentation. As the relationship between long sleep duration and increased risk of cardiovascular-related and cancer-related mortality is unique to the elderly population, the causality should be further investigated.

\section{Normative sleep duration values across the lifespan}

Sleep-wake regulation and sleep states evolve very rapidly during the first year of life. ${ }^{40}$ For example, newborns (0-3 months) do not have an established circadian rhythm and therefore their sleep is distributed across the full 24-hour day. ${ }^{41}$ At $10-12$ weeks, the circadian rhythm emerges and sleep becomes more nocturnal between ages 4 and 12 months. ${ }^{42}$ Children continue to take daytime naps between 1 and 4 years of age, and night wakings are common. ${ }^{43}$ Daytime naps typically stop by the age of 5 years and overnight sleep duration gradually declines throughout childhood, in part due to a shift to later bedtimes and unchanged wake times. ${ }^{43}$

Sleep patterns are explained by a complex interplay between genetic, behavioral, environmental, and social factors. Examples of factors that can determine sleep duration include daycare/school schedules, parenting practices, cultural preferences, family routines, and individual differences in genetic makeup. Despite inter-individual differences in sleep duration, international normative data exist to show the 
normal distribution of sleep duration for different age groups. However, it is important to keep in mind that normative reference values by no means indicate anything about what the ideal or optimal sleep duration should be, ie, the amount of sleep associated with health benefits. Nevertheless, they tell us about what is normal (or not) in the population and provide a valuable yardstick for practitioners and educators when dealing with sleep-related issues.

A meta-analysis by Galland et $\mathrm{al}^{44}$ examined the scientific literature with regards to normal sleep patterns in infants and children aged $0-12$ years. The review included 69,542 participants from 18 countries and subjective measures were used to determine sleep duration (sleep diary or questionnaire). They calculated mean reference values and ranges $( \pm 1.96$ $\mathrm{SD})$ for sleep duration of $12.7 \mathrm{~h} /$ day $(9.0-13.3)$ for infants (<2 years), $11.9 \mathrm{~h} /$ day (9.9-13.8) for toddlers/preschoolers (ages 2-5 years), and 9.2 h/day (7.6-10.8) for children (6-12 years). Normative sleep duration data across age categories are shown in Figure 1. A strong inverse relationship with age was evident from these data, with the fastest rate of decline observed over the first 6 months of life $(10.5 \mathrm{~min} / \mathrm{month}$ decline in sleep duration). The review also highlighted that Asians had significantly shorter sleep (1 hour less over the 0-12-year range) compared to Caucasians or other ethnic groups. Overall, these reference values should be considered as global norms because the authors combined different countries and cultures.

Galland et $\mathrm{al}^{45}$ also reported in 2018 normative sleep duration values for children aged 3-18 years as measured with actigraphy (objective assessment of sleep duration). Their meta-analysis included 79 articles and involved children from 17 countries. As shown in Figure 2, pooled mean estimates for overnight sleep duration declined from 9.68 hours (3-5 years age band) to 8.98 hours (6-8 years age band), 8.85 hours (9-11 years age band), 8.05 hours (12-14 years age band), and 7.4 hours (15-18 years age band). These normative sleep duration values may aid in the interpretation of actigraphy measures from nighttime recordings in the pediatric population for any given age.

A meta-analysis of objectively assessed sleep from childhood to adulthood was also published by Ohayon et $\mathrm{al}^{46}$ in 2004 to determine normative sleep values across the lifespan. A total of 65 studies representing 3,577 healthy individuals aged 5-102 years were included. Polysomnography or actigraphy was used to assess sleep duration in the included studies. They observed that total sleep time significantly

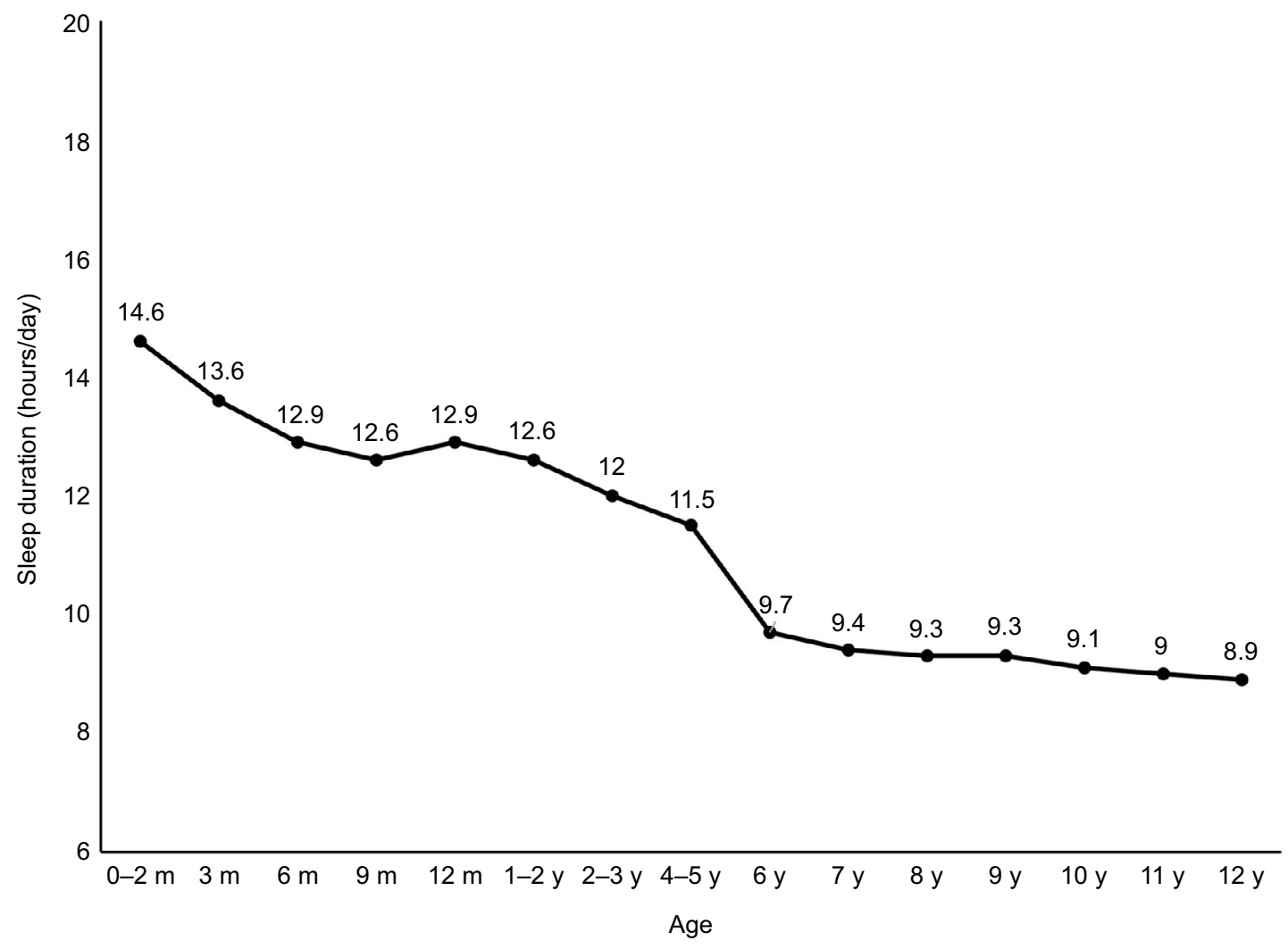

Figure I Normal self-reported sleep durations in children aged 0-12 years.

Note: The mean reference values are from a meta-analysis of 34 studies from 18 countries. $^{44}$

Abbreviations: $\mathrm{m}$, months; $y$, years. 


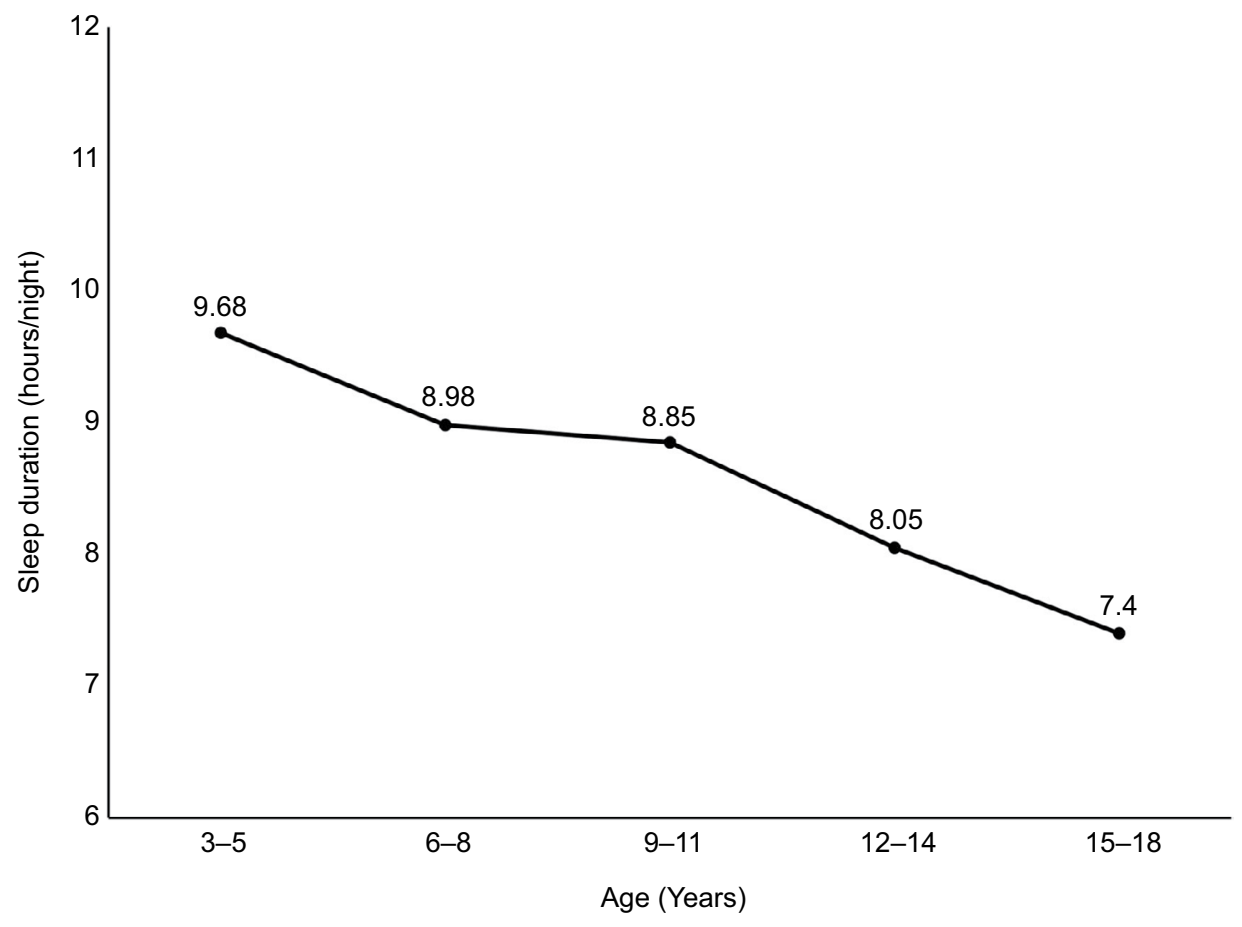

Figure 2 Normal actigraphy-determined sleep duration values in children aged 3-18 years.

Note: The mean reference values are from a meta-analysis of 79 studies from 17 countries. $^{45}$

decreased with age in adults, while it was the case in children and adolescents only in studies performed on school days. This pattern suggests that, in children and adolescents, the decrease in total sleep time is not related to maturation but to other factors such as earlier school start times.

In summary, normative sleep duration values are helpful in providing information on what constitutes the norm for a given age and what is considered outside the norm. These reference values are impacted by the method used to determine sleep duration (objective vs subjective assessment) and provide norms at the population-level standpoint. Many factors can determine sleep duration at the individual level. Although international normative data provide information about the normal distribution of sleep duration in the population, they do not identify the duration associated with health benefits. For example, having a sleep duration that fits with the average of the population is by no means indicative of either a good or a bad sleep amount. Optimal sleep duration, or the amount of sleep associated with favorable outcomes, is what is used for public health recommendations and is discussed in the next section.

\section{Recommended amount of sleep across the lifespan}

In 2015, the National Sleep Foundation in the US released their updated sleep duration recommendations to make scien- tifically sound and practical recommendations for daily sleep duration across the lifespan. ${ }^{47}$ The same year, the American Academy of Sleep Medicine and the Sleep Research Society released a consensus recommendation for the amount of sleep needed to promote optimal health in adults. ${ }^{48}$ The year after, they released their recommended amount of sleep for pediatric populations. ${ }^{49}$ Both sleep guidelines issued by the US used a similar developmental approach to deliver their sleep duration recommendations, which included a consensus and a voting process with a multidisciplinary expert panel. The sleep duration recommendations can be found in Table 1.

Many organizations around the world have their own sleep duration recommendations, and the aim of this article is not to review the different sleep duration guidelines. Overall, they are all very similar, and often reference the recommendations from the US. In Canada, robust and evidence-informed sleep guidelines became available in 2016..$^{50,51}$ The sleep recommendations in Canada for children of all ages, also known as the 24-hour guidelines, are integrated with physical activity and sedentary behavior recommendations to cover the entire 24-hour period (sleep/wake period). This allows to put more emphasis on the overall "cocktail" of behaviors for a healthier 24-hour day, rather than isolating individual behaviors. This integrated approach to health, with a focus on the interrelationships among sleep, sedentary behavior, and physical activity, is an important advancement in public 
Table I Sleep duration recommendations in the US and Canada

\begin{tabular}{|c|c|c|c|c|c|}
\hline \multicolumn{2}{|c|}{$\begin{array}{l}\text { National sleep foundation } \\
\text { (US) }\end{array}$} & \multicolumn{2}{|l|}{$\begin{array}{l}\text { AASM/SRS } \\
\text { (US) }\end{array}$} & \multicolumn{2}{|c|}{$\begin{array}{l}\text { 24-hour movement guidelines } \\
\text { (Canada) }\end{array}$} \\
\hline Age group & Recommendation & Age group & Recommendation & Age group & Recommendation \\
\hline $\begin{array}{l}\text { Newborns } \\
\text { (0-3 months) }\end{array}$ & $14-17$ hours & $\begin{array}{l}\text { Newborns } \\
\text { (0-3 months) }\end{array}$ & Not included & $\begin{array}{l}\text { Newborns } \\
\text { (0-3 months) }\end{array}$ & 14-17 hours \\
\hline $\begin{array}{l}\text { Infants } \\
\text { (4-II months) }\end{array}$ & $12-15$ hours & $\begin{array}{l}\text { Infants } \\
\text { (4-II months) }\end{array}$ & $12-16$ hours & $\begin{array}{l}\text { Infants } \\
\text { (4-II months) }\end{array}$ & $12-16$ hours \\
\hline $\begin{array}{l}\text { Toddlers } \\
\text { (I-2 years) }\end{array}$ & $11-14$ hours & $\begin{array}{l}\text { Toddlers } \\
\text { ( } 1-2 \text { years })\end{array}$ & $11-14$ hours & $\begin{array}{l}\text { Toddlers } \\
\text { (I-2 years) }\end{array}$ & $11-14$ hours \\
\hline $\begin{array}{l}\text { Preschoolers } \\
\text { (3-5 years) }\end{array}$ & $10-13$ hour & $\begin{array}{l}\text { Preschoolers } \\
\text { ( } 3-5 \text { years) }\end{array}$ & $10-13$ hours & $\begin{array}{l}\text { Preschoolers } \\
\text { (3-4 years) }\end{array}$ & $10-13$ hours \\
\hline $\begin{array}{l}\text { Children } \\
(6-13 \text { years })\end{array}$ & 9-1I hours & $\begin{array}{l}\text { Children } \\
(6-12 \text { years })\end{array}$ & $9-12$ hours & $\begin{array}{l}\text { Children } \\
\text { (5-13 years) }\end{array}$ & $9-11$ hours \\
\hline $\begin{array}{l}\text { Teenagers } \\
\text { (14-17 years) }\end{array}$ & $8-10$ hours & $\begin{array}{l}\text { Teenagers } \\
\text { (13-17 years })\end{array}$ & $8-10$ hours & $\begin{array}{l}\text { Teenagers } \\
\text { (14-17 years) }\end{array}$ & $8-10$ hours \\
\hline $\begin{array}{l}\text { Young adults } \\
\text { ( } 18-25 \text { years) }\end{array}$ & 7-9 hours & $\begin{array}{l}\text { Adults } \\
\text { (18-60 years) }\end{array}$ & $\geq 7$ hours & $\begin{array}{l}\text { Adults } \\
\text { (18-64 years) }\end{array}$ & \\
\hline $\begin{array}{l}\text { Adults } \\
\text { ( } 26-64 \text { years) } \\
\text { Older adults } \\
\text { ( } \geq 65 \text { years) }\end{array}$ & $\begin{array}{l}\text { 7-9 hours } \\
7-8 \text { hours }\end{array}$ & & & $\begin{array}{l}\text { Older adults } \\
\text { ( } \geq 65 \text { years) }\end{array}$ & In development \\
\hline
\end{tabular}

Note: Papers describing the sleep duration recommendations can be found elsewhere. ${ }^{47-51}$

Abbreviations: AASM, American Academy of Sleep Medicine; SRS, Sleep Research Society.

health messaging. It emphasizes that all of these behaviors matter equally, and balancing all three is required for favorable health outcomes.

The Canadian 24-hour guidelines were the impetus for the development of similar guidelines in Australia, ${ }^{52} \mathrm{New}$ Zealand, ${ }^{53}$ and the initiation of similar global guidelines by the World Health Organization. Similar integrated 24-hour guidelines for adults and older adults are currently being developed in Canada to cover the entire lifespan. The sleep duration recommendations contained within the 24-hour movement guidelines can be found in Table 1 .

Although sleep duration recommendations are based on the best available evidence and expert consensus, they are still largely reliant on observational studies using self-reported sleep duration. More longitudinal studies and sleep restriction/extension experiments are needed to better quantify the upper and lower limits of healthy sleep duration, and the shape of the dose-response curve with a wide range of health outcomes. Current sleep duration recommendations also suggest that a generalized optimum exists for the entire population; however, it is unlikely to be the case and this optimum can vary depending on the health outcome examined. ${ }^{54}$ There is also inter-individual variability in sleep needs in that sleeping shorter or longer than the recommended amount may not necessarily result in adverse effects on health. For example, genetic differences between individuals can explain some of the variability in sleep needs. However, intention- ally restricting sleep over a prolonged period of time (ie, chronic sleep deprivation) is not a good idea and can impact health and safety. ${ }^{47}$ Thus, although sleep recommendations are a good tool for public health surveillance, they need to be adapted on a case-by-case basis in clinic (not a one-sizefits-all recommendation).

Sleep duration recommendations have ranges, or zones of optimal sleep, suggesting that the relationship between sleep duration and adverse health outcomes is U-shaped, with both extremities, sleep durations that are too short or too long, associated with negative effects on health. ${ }^{47-51}$ There is a large body of evidence providing biological plausibility for short sleep as causally related to a wide range of adverse health outcomes; however, the role of long sleep is less clear. Aside from the elderly population, long sleep is generally associated with other health problems (eg, depression, chronic pain, low socioeconomic status) that can confound the associations. ${ }^{55,56}$ Reverse causation and residual confounding are thus better mechanisms to explain the associations between long sleep and adverse health outcomes. ${ }^{55,56}$ This may explain why the American Academy of Sleep Medicine and the Sleep Research Society recommends a threshold value for adults ( $\geq 7$ hours per night) rather than a range (eg, 7-9 hours per night) (Table 1). However, excessive long sleep duration may be informative as it can be indicative of poor sleep efficiency (ie, spending a lot of time in bed but of low quality). 
Self-reported sleep duration is typically used in population health surveillance studies, because it provides several advantages (eg, inexpensive, not invasive, and logistically easy to administer to a large sample of individuals). However, the concession is that sleep duration recommendations are then largely based on self-reported data. It is well-known that self-reported sleep duration overestimates actual sleep duration. ${ }^{57}$ Thus, it would be misleading to use an objective measure of sleep duration to report the prevalence of short sleepers in a given sample; this would result in an overestimation of true short sleepers. The growing popularity of actigraphy and wearable technologies for health behavior tracking in epidemiology is nevertheless desirable for providing better sleep estimates and more precise associations with health outcomes. ${ }^{58,59}$ Sleep duration recommendations are also likely to evolve over time, as more objective measures of sleep are used in future studies. For example, an individual self-reporting 7 hours of sleep per night may actually get 6 hours if assessed objectively with actigraphy, as it can better account for total sleep by accurately measuring sleep onset and episodes of night wakings. ${ }^{60}$ Thus, using reliable tools for tracking sleep duration over time is important, and one must keep in mind that the overall sleep duration pattern is more critical to long-term health than one snapshot in time (ie, chronic effect vs acute effect of insufficient sleep on health).

Consumers have also become increasingly interested in using fitness trackers and smartphone applications to assess their sleep. These devices provide information on sleep duration and even sleep quality from in-built accelerometry but the mechanisms and algorithms are propriotery. ${ }^{61-64}$ The growing body of evidence on consumer sleep tracking devices against polysomnography/actigraphy shows that they tend to underestimate sleep disruptions and overestimate sleep duration and sleep efficiency in healthy individuals. ${ }^{61-64}$ Although consumer sleep tracking devices are changing the landscape of sleep health and have important advantages, more research is needed to better determine their utility and reduce current shortcomings. ${ }^{61-64}$

Population statistics in Canada indicate that $16 \%$ of preschoolers sleep less than recommended, while $20 \%$ of children and one-third of teenagers, adults, and older adults report less-than-recommended sleep durations for optimal health. ${ }^{65-67}$ These nationally representative surveys use subjective data and are thus comparable to the sleep duration guidelines. As shown in Figure 3, the average sleep duration of Canadians by age group is situated at the lower border of the sleep duration recommendations. On average, a large

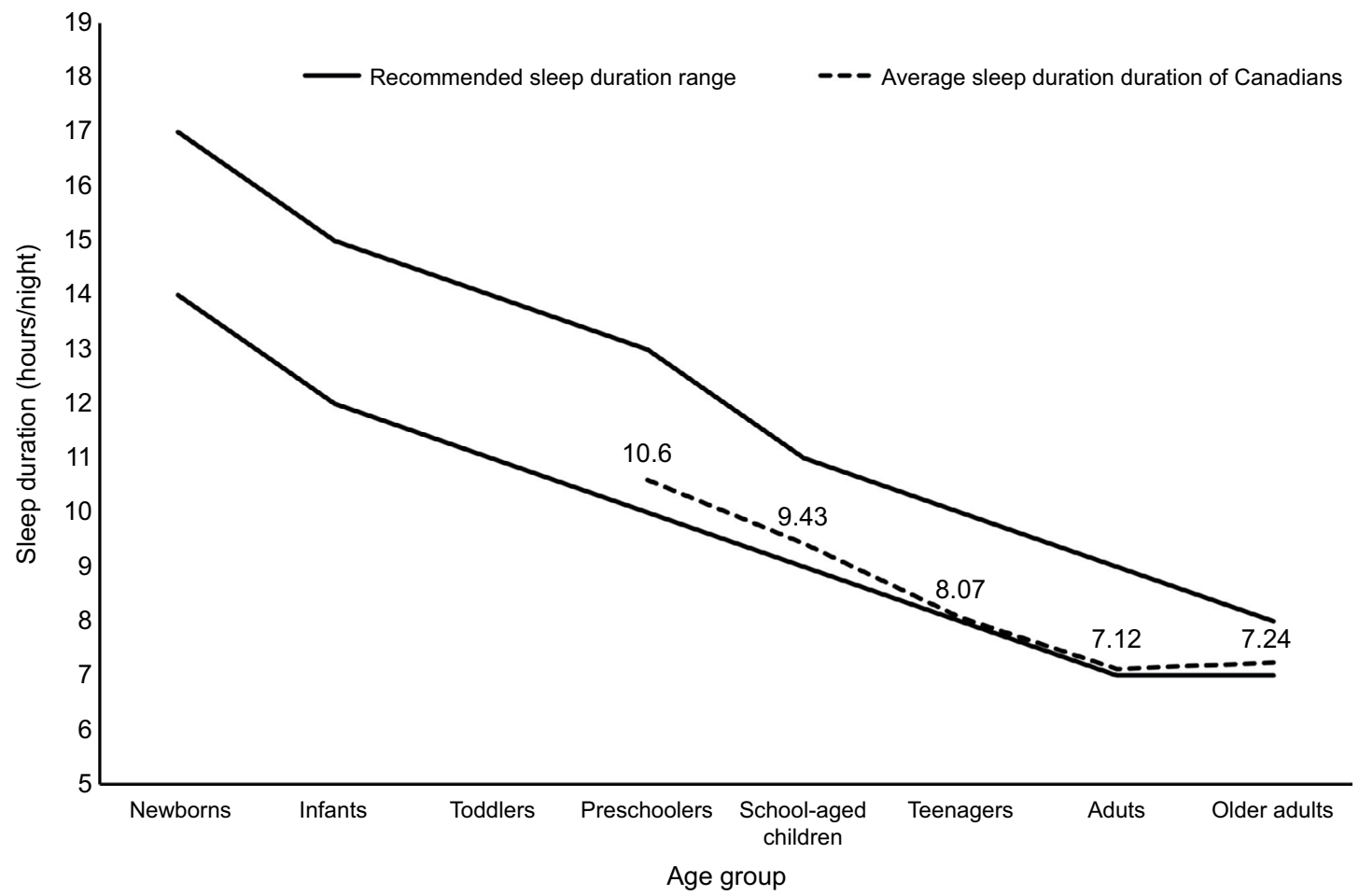

Figure 3 Sleep duration estimates of Canadians (dashed line) compared with the sleep duration recommendation ranges (solid lines).

Notes: Sleep duration estimates for the Canadian population have been recently published. ${ }^{65-67}$ However, they are not available for newborns, infants, or toddlers. Canadians sleeping less than recommended for optimal health is estimated at $16 \%$ for preschoolers, $20 \%$ for school-aged children, $30 \%$ for teenagers, $32 \%$ for adults, and $31 \%$ for older adults. 
proportion of Canadians meet the sleep duration recommendations (eg, two-third of teenagers and adults); however, a large number of individuals fail to meet the guidelines (eg, one-third of teenagers and adults). If we dig deeper, we realize that the teenage group has shown the greatest rate of decline in sleep duration in past decades, especially on school days. ${ }^{11}$ Knowing the age groups more likely to experience insufficient sleep is critical to help inform the development of interventions aimed at improving sleep (eg, having school start times not earlier than 8:30 am for highschool students). ${ }^{68-70}$

\section{Ideal amount of sleep: fact or fiction?}

As discussed in this article, there is no magic number for all in terms of the ideal sleep amount to obtain each night. Sleep duration recommendations are meant for public health guidance, but need to be individualized to each patient in the clinic. Sleep needs are determined by a complex set of factors, including our genetic makeup, environmental and behavioral factors. For example, highperformance athletes need more sleep to perform at high level and recover from their intense physical training. Sleep needs in children and adolescents can also be driven by their maturation stage, independent of their chronological age. ${ }^{46}$ This means that changes in sleep patterns may happen earlier (at a younger age) for some or at an older age for others. Objectively, our current evidence of sleep need is based on circadian, homeostatic, and ultradian processes of sleep regulation and sleep need.

The notion of "optimal sleep" is complex and poorly understood. ${ }^{71}$ The definitions of optimal sleep also vary in the literature. It is very often defined as the amount recommended by public health authorities. It has also been defined as the daily amount of sleep that allows an individual to be fully awake (ie, not sleepy), and able to sustain normal levels of performance during the day. ${ }^{72}$ Others have also defined it as the amount of sleep required to feel refreshed in the morning. ${ }^{73}$ The notion of a new definition to optimal sleep based on performance is of growing interest in the literature. For example, sleep extension interventions have been shown to improve athletic performance. ${ }^{74,75}$

However, as discussed in this article and by other sleep experts, ${ }^{76}$ there is no magic number for optimal sleep, and sleep is influenced by inter- and intra-individual factors. Similarly, in a context of sleep deprivation, individual differences in sleep homeostatic and circadian rhythm contributions to neurobehavioral impairments have been elegantly documented by Van Dongen. ${ }^{77-79}$
Optimal sleep should be conceptualized as the amount of sleep needed to optimize outcomes (eg, performance, cognitive function, mental health, physical health, quality of life, etc). This implies that there might be many dose-response curves that may differ in shape between outcomes. ${ }^{54}$ Typically, the peaks of each health outcome should fall somewhere within the recommended sleep duration range. However, the exact amount of sleep to get each night for optimizing all relevant health outcomes is not straightforward or ubiquitous as the optimal amount for one outcome may not be the same for another outcome (eg, 9 hours of sleep per night could be the ideal for athletic performance, while 7 hours could be the best for academic achievement). Also, determining the causal effects of sleep need on health is not an easy task and requires experiments (eg, interventional study designs with improved vs reduced sleep, both acutely and chronically applied, and then assessing outcomes on physiology, wellbeing, health, and behavior).

Although the present article focused on sleep duration, many other dimensions of sleep are important beyond getting a sufficient amount each night. These include aspects of sleep quality such as sleep efficiency (ie, proportion of the time in bed actually asleep), sleep timing (ie, bedtime/ wake-up times), sleep architecture (ie, sleep stages), sleep consistency (ie, day-to-day variability in sleep duration), sleep consolidation (ie, organization of sleep across the night), and sleep satisfaction. For example, the National Sleep Foundation recently released evidence-informed sleep quality recommendations for individuals across the lifespan. ${ }^{80}$ These included sleep continuity variables such as sleep latency, number of awakenings $>5$ minutes, wake after sleep onset, and sleep efficiency. Along the same lines, monophasic sleep (ie, sleeping once per day, typically at night) is considered the norm in our society but other sleep patterns (eg, biphasic or polyphasic) are also observed depending on the preference of each person or culture. Napping is increasingly seen as a public health tool and countermeasure for sleep deprivation in terms of reducing accidents and cardiovascular events and improving working performance. ${ }^{81}$

\section{Conclusion}

In summary, there is no magic number or ideal amount of sleep to get each night that could apply broadly to all. The optimal amount of sleep should be individualized, as it depends on many factors. However, it is a fair assumption to say that the optimal amount of sleep, for most people, should be within the age-appropriate sleep duration recommended ranges. Future studies should try to better inform contemporary sleep duration recommendations by examining dose- 
response curves with a wide range of health outcomes. In the meantime, promoting the importance of a good night's sleep should be a priority given its influence on other behaviors and the well-known adverse consequences of insufficient sleep. ${ }^{82}$ Important sleep hygiene tips include removing screens from the bedroom, exercising regularly during the day, and having a consistent and relaxing bedtime routine.

\section{Acknowledgment}

Jean-Philippe Chaput is a Research Scientist funded by the Children's Hospital of Eastern Ontario Research Institute (ON, Canada).

\section{Disclosure}

The authors report no conflicts of interest in this work.

\section{References}

1. Chaput JP, Gray CE, Poitras VJ, et al. Systematic review of the relationships between sleep duration and health indicators in schoolaged children and youth. Appl Physiol Nutr Metab. 2016;41(6 Suppl 3):S266-S282.

2. Chaput JP, Gray CE, Poitras VJ, et al. Systematic review of the relationships between sleep duration and health indicators in the early years (0-4 years). BMC Public Health. 2017;17(Suppl 5):855.

3. St-Onge MP, Grandner MA, Brown D, et al. Sleep duration and quality: impact on lifestyle behaviors and cardiometabolic health: a scientific statement from the American Heart Association. Circulation. 2016;134(18):e367-386.

4. Buysse DJ. Sleep health: can we define it? Does it matter? Sleep. 2014;37(1):9-17.

5. Gruber R, Carrey N, Weiss SK, et al. Position statement on pediatric sleep for psychiatrists. J Can Acad Child Adolesc Psychiatry. 2014;23(3): 174-195.

6. Owens J. Adolescent Sleep Working Group; Committee on Adolescence. Insufficient sleep in adolescents and young adults: an update on causes and consequences. Pediatrics. 2014;134(3):e921-e932.

7. Wolfson AR, Carskadon MA. Sleep schedules and daytime functioning in adolescents. Child Dev. 1998;69(4):875-887.

8. Shochat T, Cohen-Zion M, Tzischinsky O. Functional consequences of inadequate sleep in adolescents: a systematic review. Sleep Med Rev. 2014; 18(1):75-87.

9. Roehrs T, Zorick F, Sicklesteel J, Wittig R, Roth T. Excessive daytime sleepiness associated with insufficient sleep. Sleep. 1983;6(4): 319-325.

10. Institute of Medicine (US) Committee on Sleep Medicine and Research; Colten HR, Altevogt BM, editors. Sleep Disorders and Sleep Deprivation: An Unmet Public Health Problem. Washington, DC: The National Academies Press; 2006.

11. Matricciani L, Olds T, Petkov J. In search of lost sleep: secular trends in the sleep time of school-aged children and adolescents. Sleep Med Rev. 2012;16(3):203-211.

12. WuY, Zhai L, Zhang D. Sleep duration and obesity among adults: a metaanalysis of prospective studies. Sleep Med. 2014;15(12):1456-1462.

13. Shan Z, Ma H, Xie M, et al. Sleep duration and risk of type 2 diabetes: a meta-analysis of prospective studies. Diabetes Care. 2015;38(3): 529-537.

14. Wang Y, Mei H, Jiang YR, et al. Relationship between duration of sleep and hypertension in adults: a meta-analysis. J Clin Sleep Med. 2015;11(9):1047-1056.

15. Wang D, Li W, Cui X, et al. Sleep duration and risk of coronary heart disease: A systematic review and meta-analysis of prospective cohort studies. Int J Cardiol. 2016;219:231-239.
16. Zhai L, Zhang H, Zhang D. Sleep duration and depression among adults: a meta-analysis of prospective studies. Depress Anxiety. 2015;32(9):664-670.

17. Shen X, Wu Y, Zhang D. Nighttime sleep duration, 24-hour sleep duration and risk of all-cause mortality among adults: a meta-analysis of prospective cohort studies. Sci Rep. 2016;6:21480.

18. Barnes CM, Drake CL. Prioritizing sleep health: public health policy recommendations. Perspect Psychol Sci. 2015;10(6):733-737.

19. Chaput JP, Dutil C. Lack of sleep as a contributor to obesity in adolescents: impacts on eating and activity behaviors. Int J Behav Nutr Phys Act. 2016;13(1):103.

20. Chaput JP, Carson V, Gray CE, Tremblay MS. Importance of all movement behaviors in a 24 hour period for overall health. Int J Environ Res Public Health. 2014;11(12):12575-12581.

21. Chaput JP, Janssen I. Sleep duration estimates of Canadian children and adolescents. J Sleep Res. 2016;25(5):541-548.

22. Bartel KA, Gradisar M, Williamson P. Protective and risk factors for adolescent sleep: a meta-analytic review. Sleep Med Rev. 2015;21:72-85.

23. Chaput JP, Tremblay MS, Katzmarzyk PT, et al. Sleep patterns and sugar-sweetened beverage consumption among children from around the world. Public Health Nutr. 2018;21(13):2385-2393.

24. Sampasa-Kanyinga H, Hamilton HA, Chaput JP. Sleep duration and consumption of sugar-sweetened beverages and energy drinks among adolescents. Nutrition. 2018;48:77-81.

25. Sampasa-Kanyinga H, Hamilton HA, Chaput JP. Use of social media is associated with short sleep duration in a dose-response manner in students aged 11 to 20 years. Acta Paediatr. 2018;107(4):694-700.

26. Carskadon MA, Vieira C, Acebo C. Association between puberty and delayed phase preference. Sleep. 1993;16(3):258-262.

27. Kelley P, Lockley SW, Foster RG, Kelley J. Synchronizing education to adolescent biology: 'let teens sleep, start school later'. Learn Media Technol. 2015;40(2):210-226.

28. Adan A, Archer SN, Hidalgo MP, di Milia L, Natale V, Randler C. Circadian typology: a comprehensive review. Chronobiol Int. 2012;29(9):1153-1175

29. Edwards BA, O’Driscoll DM, Ali A, Jordan AS, Trinder J, Malhotra A. Aging and sleep: physiology and pathophysiology. Semin Respir Crit Care Med. 2010;31(5):618-633.

30. Foley DJ, Monjan AA, Brown SL, Simonsick EM, Wallace RB, Blazer DG. Sleep complaints among elderly persons: an epidemiologic study of three communities. Sleep. 1995;18(6):425-432.

31. Foley D, Ancoli-Israel S, Britz P, Walsh J. Sleep disturbances and chronic disease in older adults: results of the 2003 National Sleep Foundation Sleep in America Survey. J Psychosom Res. 2004;56(5):497-502.

32. Vitiello MV, Moe KE, Prinz PN. Sleep complaints cosegregate with illness in older adults. J Psychosom Res. 2002;53(1):555-559.

33. Ancoli-Israel S, Kripke DF, Klauber MR, Mason WJ, Fell R, Kaplan O. Periodic limb movements in sleep in community-dwelling elderly. Sleep. 1991;14(6):496-500.

34. Bailes S, Baltzan M, Alapin I, Fichten CS, Libman E. Diagnostic indicators of sleep apnea in older women and men: a prospective study. $J$ Psychosom Res. 2005;59(6):365-373.

35. Young T, Palta M, Dempsey J, Skatrud J, Weber S, Badr S. The occurrence of sleep-disordered breathing among middle-aged adults. $N E n g l$ J Med. 1993;328(17):1230-1235.

36. Ancoli-Israel S, Ayalon L. Diagnosis and treatment of sleep disorders in older adults. Am J Geriatr Psychiatry. 2006;14(2):95-103.

37. Neikrug AB, Ancoli-Israel S. Sleep disorders in the older adult - a mini-review. Gerontology. 2010;56(2):181-189.

38. Grandner MA, Drummond SP. Who are the long sleepers? Towards an understanding of the mortality relationship. Sleep Med Rev. 2007;11(5): 341-360.

39. Edwards BA, O’Driscoll DM, Ali A, Jordan AS, Trinder J, Malhotra A. Aging and sleep: physiology and pathophysiology. Semin Respir Crit Care Med. 2010;31(5):618-633.

40. Mclaughlin Crabtree V, Williams NA. Normal sleep in children and adolescents. Child Adolesc Psychiatr Clin NAm. 2009;18(4):799-811. 
41. Davis KF, Parker KP, Montgomery GL. Sleep in infants and young children: Part one: normal sleep. J Pediatr Health Care. 2004;18(2): 65-71.

42. Sheldon SH, Sateia MJ, Carskadon MA. Sleep in infants and children. In: Lee-Chiong TL, Sateia MJ, Carskadon MA, editors. Sleep Medicine. Philadelphia, PA: Hanley and Belfus Inc; 2002:99-103.

43. Iglowstein I, Jenni OG, Molinari L, Largo RH. Sleep duration from infancy to adolescence: reference values and generational trends. Pediatrics. 2003;111(2):302-307.

44. Galland BC, Taylor BJ, Elder DE, Herbison P. Normal sleep patterns in infants and children: a systematic review of observational studies. Sleep Med Rev. 2012;16(3):213-222.

45. Galland BC, Short MA, Terrill P, et al. Establishing normal values for pediatric nighttime sleep measured by actigraphy: a systematic review and meta-analysis. Sleep. 2018;41(4).

46. Ohayon MM, Carskadon MA, Guilleminault C, Vitiello MV. Metaanalysis of quantitative sleep parameters from childhood to old age in healthy individuals: developing normative sleep values across the human lifespan. Sleep. 2004;27(7):1255-1273.

47. Hirshkowitz M, Whiton K, Albert SM, et al. National Sleep Foundation's updated sleep duration recommendations: final report. Sleep Health. 2015;1(4):233-243.

48. Consensus Conference Panel, Watson NF, Badr MS, et al. Joint consensus statement of the American Academy of Sleep Medicine and Sleep Research Society on the recommended amount of sleep for a healthy adult: methodology and discussion. Sleep. 2015;38(8):1161-1183.

49. Paruthi S, Brooks LJ, D’Ambrosio C, et al. Recommended amount of sleep for pediatric populations: a consensus statement of the American Academy of Sleep Medicine. J Clin Sleep Med. 2016;12(6): 785-786.

50. Tremblay MS, Carson V, Chaput JP. Canadian 24-hour movement guidelines for children and youth: an integration of physical activity, sedentary behaviour, and sleep. Appl Physiol Nutr Metab. 2016;41(6 Suppl 3):S311-327.

51. Tremblay MS, Chaput JP, Adamo KB, et al. Canadian 24-hour movement guidelines for the early years (0-4 years): an integration of physical activity, sedentary behaviour, and sleep. BMC Public Health. 2017;17(Suppl 5):874.

52. Okely AD, Ghersi D, Hesketh KD, et al. A collaborative approach to adopting/adapting guidelines - The Australian 24-Hour Movement Guidelines for the early years (Birth to 5 years): an integration of physical activity, sedentary behavior, and sleep. BMC Public Health. 2017;17(Suppl 5):869.

53. New Zealand Ministry of Health. Sit Less, Move More, Sleep Well: Active Play Guidelines for Under-Fives. Wellington: New Zealand, Ministry of Health; 2017.

54. Matricciani L, Blunden S, Rigney G, Williams MT, Olds TS. Children's sleep needs: is there sufficient evidence to recommend optimal sleep for children? Sleep. 2013;36(4):527-534.

55. Stamatakis KA, Punjabi NM. Long sleep duration: a risk to health or a marker of risk? Sleep Med Rev. 2007;11(5):337-339.

56. Knutson KL, Turek FW. The U-shaped association between sleep and health: the 2 peaks do not mean the same thing. Sleep. 2006;29(7):878-879.

57. Girschik J, Fritschi L, Heyworth J, Waters F. Validation of self-reported sleep against actigraphy. J Epidemiol. 2012;22(5):462-468.

58. Meltzer LJ, Montgomery-Downs HE, Insana SP, Walsh CM. Use of actigraphy for assessment in pediatric sleep research. Sleep Med Rev. 2012;16(5):463-475.

59. Sadeh A. The role and validity of actigraphy in sleep medicine: an update. Sleep Med Rev. 2011;15(4):259-267.
60. Cespedes EM, Hu FB, Redline S, et al. Comparison of self-reported sleep duration with actigraphy: results from the hispanic community health study/study of Latinos Sueño Ancillary Study. Am J Epidemiol. 2016;183(6):561-573

61. Lorenz CP, Williams AJ. Sleep apps: what role do they play in clinical medicine? Curr Opin Pulm Med. 2017;23(6):512-516.

62. Mansukhani MP, Kolla BP. Apps and fitness trackers that measure sleep: Are they useful? Cleve Clin J Med. 2017;84(6):451-456.

63. Kolla BP, Mansukhani S, Mansukhani MP. Consumer sleep tracking devices: a review of mechanisms, validity and utility. Expert Rev Med Devices. 2016;13(5):497-506.

64. Ko PR, Kientz JA, Choe EK, Kay M, Landis CA, Watson NF. Consumer sleep technologies: a review of the landscape. J Clin Sleep Med. 2015;11(12):1455-1461.

65. Chaput JP, Colley RC, Aubert S, et al. Proportion of preschool-aged children meeting the Canadian 24-Hour Movement Guidelines and associations with adiposity: results from the Canadian Health Measures Survey. BMC Public Health. 2017;17(Suppl 5):829.

66. Michaud I, Chaput JP. Are Canadian children and adolescents sleep deprived? Public Health. 2016;141:126-129.

67. Chaput JP, Wong SL, Michaud I. Duration and quality of sleep among Canadians aged 18 to 79. Health Rep. 2017;28(9):28-33.

68. Adolescent Sleep Working Group. Committee on Adolescence; Council on School Health. School start times for adolescents. Pediatrics. 2014;134(3):642-649.

69. Minges KE, Redeker NS. Delayed school start times and adolescent sleep: A systematic review of the experimental evidence. Sleep Med Rev. 2016;28:86-95.

70. Hafner M, Stepanek M, Troxel WM. The economic implications of later school start times in the United States. Sleep Health. 2017;3(6):451-457.

71. Matricciani L, Bin YS, Lallukka T, et al. Past, present, and future: trends in sleep duration and implications for public health. Sleep Health. 2017;3(5):317-323

72. Ferrara M, De Gennaro L. How much sleep do we need? Sleep Med Rev. 2001;5(2):155-179.

73. Engle-Friedman M, Palencar V, Riela S. Sleep and effort in adolescent athletes. J Child Health Care. 2010;14(2):131-141.

74. Bonnar D, Bartel K, Kakoschke N, Lang C. Sleep interventions designed to improve athletic performance and recovery: a systematic review of current approaches. Sports Med. 2018;48(3):683-703.

75. Mah CD, Mah KE, Kezirian EJ, Dement WC. The effects of sleep extension on the athletic performance of collegiate basketball players. Sleep. 2011;34(7):943-950.

76. Horne J. Sleepiness as a need for sleep: when is enough, enough? Neurosci Biobehav Rev. 2010;34(1):108-118.

77. Van Dongen HP, Bender AM, Dinges DF. Systematic individual differences in sleep homeostatic and circadian rhythm contributions to neurobehavioral impairment during sleep deprivation. Accid Anal Prev. 2012;45(Suppl):11-16.

78. Van Dongen HP, Caldwell JA, Caldwell JL. Individual differences in cognitive vulnerability to fatigue in the laboratory and in the workplace. Prog Brain Res. 2011;190:145-153.

79. Van Dongen HP, Belenky G. Individual differences in vulnerability to sleep loss in the work environment. Ind Health. 2009;47(5):518-526.

80. Ohayon M, Wickwire EM, Hirshkowitz M, et al. National Sleep Foundation's sleep quality recommendations: first report. Sleep Health. 2017;3(1):6-19.

81. Faraut B, Andrillon T, Vecchierini MF, Leger D. Napping: a public health issue. From epidemiological to laboratory studies. Sleep Med Rev. 2017;35:85-100

82. Chaput JP. The integration of pediatric sleep health into public health in Canada. Sleep Med. Epub 2018 Jun 30. 
Nature and Science of Sleep is an international, peer-reviewed, open access journal covering all aspects of sleep science and sleep medicine, including the neurophysiology and functions of sleep, the genetics of sleep, sleep and society, biological rhythms, dreaming, sleep disorders and therapy, and strategies to optimize healthy sleep. The manuscript management system is completely online and includes a very quick and fair peer-review system, which is all easy to use. Visit http://www. dovepress.com/testimonials.php to read real quotes from published authors.

Submit your manuscript here: https://www.dovepress.com/cancer-management-and-research-journal 